\title{
Whole brain radiotherapy plus simultaneous in-field boost with image guided intensity-modulated radiotherapy for brain metastases of non-small cell lung cancer
}

Lin Zhou ${ }^{1 \dagger}$, Jia Liư ${ }^{2+}$, Jianxin Xue ${ }^{1}$, Yong X ${ }^{1}$, Youling Gong ${ }^{1}$, Lei Deng ${ }^{1}$, Shichao Wang ${ }^{3}$, Renming Zhong ${ }^{3}$, Zhenyu Ding ${ }^{1}$ and You Lu ${ }^{1,4^{*}}$

\begin{abstract}
Background: Whole brain radiotherapy (WBRT) plus sequential focal radiation boost is a commonly used therapeutic strategy for patients with brain metastases. However, recent reports on WBRT plus simultaneous in-field boost (SIB) also showed promising outcomes. The objective of present study is to retrospectively evaluate the efficacy and toxicities of WBRT plus SIB with image guided intensity-modulated radiotherapy (IG-IMRT) for inoperable brain metastases of NSCLC.

Methods: Twenty-nine NSCLC patients with 87 inoperable brain metastases were included in this retrospective study. All patients received WBRT at a dose of $40 \mathrm{~Gy} / 20 \mathrm{f}$, and SIB boost with IG-IMRT at a dose of $20 \mathrm{~Gy} / 5 \mathrm{f}$ concurrent with WBRT in the fourth week. Prior to each fraction of IG-IMRT boost, on-line positioning verification and correction were used to ensure that the set-up errors were within $2 \mathrm{~mm}$ by cone beam computed tomography in all patients.

Results: The one-year intracranial control rate, local brain failure rate, and distant brain failure rate were $62.9 \%, 13.8 \%$, and $19.2 \%$, respectively. The two-year intracranial control rate, local brain failure rate, and distant brain failure rate were $42.5 \%, 30.9 \%$, and $36.4 \%$, respectively. Both median intracranial progression-free survival and median survival were 10 months. Six-month, one-year, and two-year survival rates were $65.5 \%, 41.4 \%$, and $13.8 \%$, corresponding to $62.1 \%, 41.4 \%$, and $10.3 \%$ of intracranial progression-free survival rates. Patients with Score Index for Radiosurgery in Brain Metastases (SIR) $>5$, number of intracranial lesions $<3$, and history of EGFR-TKI treatment had better survival. Three lesions (3.45\%) demonstrated radiation necrosis after radiotherapy. Grades 2 and 3 cognitive impairment with grade 2 radiation leukoencephalopathy were observed in 4 (13.8\%) and 4 (13.8\%) patients. No dosimetric parameters were found to be associated with these late toxicities. Patients received EGFR-TKI treatment had higher incidence of grades 2-3 cognitive impairment with grade 2 leukoencephalopathy.
\end{abstract}

Conclusions: WBRT plus SIB with IG-IMRT is a tolerable and effective treatment for NSCLC patients with inoperable brain metastases. However, the results of present study need to be examined by the prospective investigations.

Keywords: Whole brain radiotherapy, Simultaneous in-field boost, Brain metastases, Non-small cell lung cancer

\footnotetext{
* Correspondence: radyoulu@hotmail.com

${ }^{\dagger}$ Equal contributors

'Department of Thoracic Cancer, Cancer Center, West China Hospital of

Sichuan University, Chengdu, Sichuan Province, China

${ }^{4}$ State Key Laboratory of Biotherapy, West China Hospital of Sichuan

University, Chengdu, Chengdu, Sichuan Province, China

Full list of author information is available at the end of the article
} 


\section{Background}

Non-small cell lung cancer (NSCLC) is one of the most common malignant tumors, and approximately 36\%-44\% of patients with NSCLC present with brain metastases during the course of disease [1]. During the past 50 years, whole brain radiotherapy (WBRT) has been the standard treatment for brain metastases, but its therapeutic effects are suboptimal with intracranial control rate (ICR) of $60 \%$ and median survival of 3-6 months $[1,2]$. Stereotactic radiosurgery (SRS) is beneficial in patients with limited number and volume of metastases and it has become increasingly available as an alternative focal treatment to surgery, but its therapeutic effects decrease with increasing number and volume of lesions [3]. Furthermore, SRS is not recommended in patients with lesions located in or close to critical anatomic structures because of unacceptable risk of severe long-term damage [3]. Hypofractionated stereotactic radiotherapy (hfSRT) combines the precise beam delivery of radiosurgical technique with the radiobiological advantages of fractionation, and has shown the results comparable to SRS [4].

Noncoplanar arcs, noncoplanar fixed fields and intensity modulation are the most frequently used stereotactic radiotherapy techniques. It has been reported that intensity-modulated radiotherapy (IMRT) technique results in improved dose conformity as compared to the other two techniques for the hemisphere and irregular tumor targets, and may increase the therapeutic ratio of treating large and/or irregularly shaped intracranial lesions [5]. Image guided intensity-modulated radiotherapy (IGIMRT) is a new technique of radiotherapy. It improves the accuracy of treatment delivery by using cone beam computed tomography (CBCT) with $\mathrm{x}$-ray volumetric images (XVI) to give the 3-dimensional anatomic information in the treatment position and to reduce setup uncertainty [6]. With these advantages, it is possible to administer hfSRT with IG-IMRT to brain metastases with noninvasive head fixation such as thermoplastic mask [6,7].

Several prospective trials proved the superiority of WBRT plus focal radiotherapy boost in patients with limited number and volume of brain metastases [8,9], and even in patients with a large number and volume of brain metastases, several studies indicated that focal hfSRT may be effective $[10,11]$. Radiotherapy schedules of most previous reports were WBRT plus sequential SRS/hfSRT boost. Recently, some reports showed that WBRT plus simultaneous in-field boost (SIB) with helical tomotherapy were effective and tolerable for brain metastases [12-15]. In our department, $40 \mathrm{~Gy} / 20 \mathrm{f}$ (5 f/week) used to be the standard schedule of WBRT, and some NSCLC patients with brain metastases received SIB with IG-IMRT in the fourth week of WBRT if they had no or only mild neurological symptoms during the first three weeks. Therefore, we conducted this retrospective study to evaluate the efficacy and toxicities of WBRT plus SIB with IG-IMRT for NSCLC patients with brain metastases.

\section{Methods}

\section{Clinical information}

From July 2006 to April 2009, 29 NSCLC patients with a total of 87 brain metastases were treated with WBRT plus SIB with IG-IMRT in our department. All of these patients had Karnofsky Performance Status (KPS) scores $\geq 50$, and inoperable brain metastases determined by experienced neurosurgeons. Of these 29 patients, 11 received epidermal growth factor receptor tyrosine kinase inhibitor (EGFR-TKI) treatment ( 9 with gefinitib, 2 with erlotinib) concurrent with and maintained after radiotherapy. Detailed patient characteristics are summarized in Table 1 . This retrospective study was approved and governed by the Review Board of West China Hospital of Sichuan University.

\section{Treatment planning and delivery}

All patients received WBRT at a dose of $40 \mathrm{~Gy} / 20 \mathrm{f}$ (5 f/ week), and SIB with IG-IMRT at a dose of $20 \mathrm{~Gy} / 5 \mathrm{f}$ concurrent with WBRT in the fourth week. Under this schedule of radiotherapy, intracranial lesions had received total boost dose of $30 \mathrm{~Gy} / 5 \mathrm{f}$, and the biological effective dose (BED) value based on linear-quadratic (LQ) model $(B E D=$ nd $[1+d /(\alpha / \beta)], \alpha / \beta=10$ Gy) was close to the SRS boost of $15-18 \mathrm{~Gy} / 1 \mathrm{f}$ used to apply in our department. All patients were immobilized in non-invasive tight thermoplastic head masks (Med-Tec, U.S.A) and were treated by Synergy linear accelerator (Elekta, Sweden) with 6MV X-ray. Helical CT images of $3 \mathrm{~mm}$ slice thickness (Sensation 4, Siemens, Germany) were obtained by using the Precise Plan System (Version 2.11, Elekta, Sweden) and were fused with the previously generated MRI of $3 \mathrm{~mm}$ slice thickness (sonata maestro class, Siemens, Germany) by the image fusion system software. Clinical target volume (CTV) was defined as the whole brain. Planning target volume (PTV) was defined by adding a $3 \mathrm{D}$ isotropic margin of $5 \mathrm{~mm}$ to the CTV according to set-up inaccuracy. Gross tumor volume of lesion (GTV-L) was defined as the contrast enhancing tumor on MRI T1 scans. CTV of lesion (CTV-L) was defined as identical with GTV-L. PTV of lesion (PTV-L) was defined by adding a 3D isotropic margin of $2 \mathrm{~mm}$ to the GTV-L according to set-up inaccuracy. Inverse coplanar IMRT planning was used to ensure that $95 \%$ of PTV was covered by $100 \%$ isodose envelope of $40 \mathrm{~Gy}$, and $100 \%$ of PTV-L was covered by $100 \%$ isodose envelope of $60 \mathrm{~Gy}$. All patients underwent on-line positioning verification and correction to ensure that the set-up errors were within $2 \mathrm{~mm}$ by XVI 3D VolumeView imaging CBCT (Elekta, Sweden) prior to each IG-IMRT boost. Planning $\mathrm{CT}$ and VolumeView images were registered using 


\section{Table 1 Patient characteristics}

\begin{tabular}{|c|c|}
\hline Characteristics & No. of patients(\%) \\
\hline \multicolumn{2}{|l|}{ Gender } \\
\hline Male & $20(68.97)$ \\
\hline Female & $9(31.03)$ \\
\hline \multicolumn{2}{|l|}{ Age(years) } \\
\hline Median & 58 \\
\hline Range & $36-75$ \\
\hline$\geq 60$ & $13(44.83)$ \\
\hline$<60$ & $16(55.17)$ \\
\hline \multicolumn{2}{|l|}{ KPS scores } \\
\hline$\geq 70$ & $19(65.52)$ \\
\hline$<70$ & $10(34.48)$ \\
\hline \multicolumn{2}{|l|}{ Pathology } \\
\hline Adenocarcinoma & $18(62.07)$ \\
\hline Non-adenocarcinoma & $11(37.93)$ \\
\hline \multicolumn{2}{|l|}{ RPA class } \\
\hline 2 & $19(65.52)$ \\
\hline 3 & $10(34.48)$ \\
\hline \multicolumn{2}{|l|}{ SIR scores } \\
\hline$\leq 5$ & $13(44.83)$ \\
\hline$>5$ & $16(55.17)$ \\
\hline \multicolumn{2}{|l|}{ GPA scores } \\
\hline $0-1$ & $13(44.83 \%)$ \\
\hline $1.5-2$ & $11(37.93 \%)$ \\
\hline $2.5-3$ & $3(10.34 \%)$ \\
\hline 3.5 & $2(6.90 \%)$ \\
\hline \multicolumn{2}{|c|}{ History of EGFR-TKI treatment } \\
\hline Yes & $11(37.93)$ \\
\hline No & $18(62.07)$ \\
\hline \multicolumn{2}{|l|}{ Number of lesions } \\
\hline Mean & 3 \\
\hline$<3$ & $15(51.72)$ \\
\hline$\geq 3$ & $14(48.28)$ \\
\hline \multicolumn{2}{|l|}{ Maximum lesion volume } \\
\hline$<3 c c$ & $12(41.38)$ \\
\hline$\geq 3 \mathrm{cc}$ & $17(58.62)$ \\
\hline \multicolumn{2}{|l|}{ Total volume of lesions } \\
\hline$<7 \mathrm{CC}$ & $15(51.72)$ \\
\hline$\geq 7 \mathrm{cc}$ & $14(48.28)$ \\
\hline Total & 29 \\
\hline
\end{tabular}

Abbreviations: KPS = Karnofsky performance status; RPA = recursive partitioning analysis; $\mathrm{SIR}=$ score index for radiosurgery in brain metastases; GPA = graded prognostic assessment; EGFR-TKI = epidermal growth factor receptor tyrosine kinase inhibitor. automatic image registration (bone match) in the XVI software. Steroids were administered to all patients in the fourth week of radiotherapy and if patients were symptomatic in the first three weeks (see Figure 1 for the treatment schedule). All patients had completed the treatment successfully.

\section{Follow-up and statistics}

All patients were subjected to weekly neurologic examination during the radiotherapy, and underwent clinical follow-up examinations including contrast-enhanced MRI 1 month after the end of radiotherapy and every 3 months thereafter. Response evaluation was based on the World Health Organization (WHO) criteria, and assessed by measurement of enhanced lesions in T1-weighted contrastenhanced MRI image. ICR was defined as rates of complete response (CR) plus partial response (PR) and stable disease (SD) of intracranial lesions. Objective response rate (ORR) was defined as rates of $\mathrm{CR}$ plus PR of intracranial lesions. Local brain failure rate (LBFR) was defined as rate of progression of previously treated brain metastases. Regional brain failure rate (RBFR) was defined as rate of new brain metastases. Overall survival time (OS) was calculated from the day of starting radiotherapy to the last day of follow-up or death. The intracranial progressionfree survival (IC-PFS) was calculated from the day of starting radiotherapy to the day of intracranial lesions progression, death or the last day of follow-up. All side effects were evaluated according to the National Cancer Institute Common Terminology Criteria for Adverse Events (CTCAE) ver. 3.0 grading system. Side effects occurring beyond 90 days from the end of radiotherapy were considered late toxicities.

The Kaplan-Meier method was used to estimate survival curve, ICR, LBFR, and RBFR. The Log-rank test was used for univariate analysis of prognostic factors, and variables found significant in univariate analysis were further subjected to multivariate Cox-regression. The crosstabs was used for univariate analysis of the risk factors of late toxicities, and variables found significant in univariate analysis were further subjected to multivariate binary logistic regression. The independent-samples t-test was used for the dosimetry analysis. $p<0.05$ was regarded as statistically significant. All calculations were performed by SPSS 17.0.

\section{Results}

Local tumor control and survival

The median follow-up time was 10 months (range: 3-48 months), $27.6 \%(8 / 29)$ of patients died within 6 months after radiotherapy, and $72.4 \%(21 / 29)$ of patients were followed-up beyond 6 months. Up to the last follow-up visit, 13 patients had intracranial failure, with 7 new intracranial metastases and 6 locoregional progression. The ORR was $69 \%$. The one-year ICR, LBFR, and RBFR 


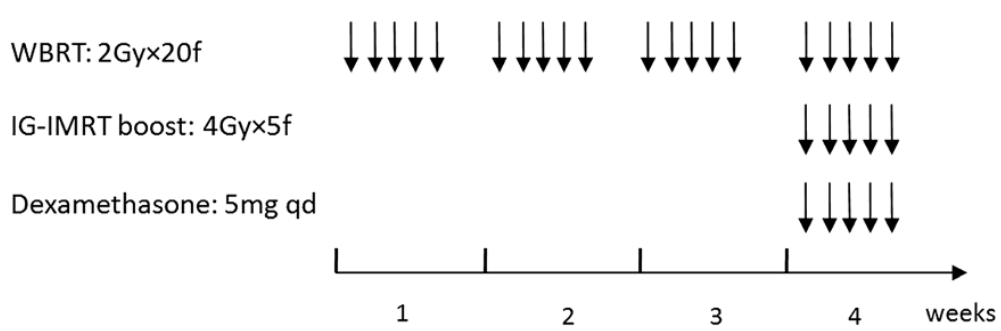

Figure 1 Treatment schedule. All patients received WBRT at a dose of $40 \mathrm{~Gy} / 20 \mathrm{f} / 4$ weeks, and SIB with IG-IMRT at a dose of $20 \mathrm{~Gy} / 5 \mathrm{f}$ concurrent with WBRT in the fourth week. Steroids (dexamethasone) were administered to all patients in the fourth week of radiotherapy. Abbreviations: WBRT = whole brain radiotherapy; IG-IMRT = image guided intensity-modulated radiotherapy; treatment delivery.

were $62.9 \%, 13.8 \%$, and $19.2 \%$, respectively. The two-year ICR, LBFR, and RBFR were $42.5 \%, 30.9 \%$, and $36.4 \%$, respectively. Twenty-one patients died due to extracranial failure and 8 died due to intracranial failure. The OS of whole patients ranged from 3 to 48 months, and the median survival (MS) was 10 months (95\% CI: 5.614.4 months). The six-month, one-year, and two-year survival rates were $65.5 \%, 41.4 \%$, and $13.8 \%$, respectively (Figure 2). The IC-PFS of whole patients ranged from 1 to 43 months, and the median IC-PFS was 10 months (95\% CI: 4.7-15.3 months). The six-month, one-year, and two-year IC-PFS rates were $62.1 \%, 41.4 \%$, and $10.3 \%$, respectively (Figure 3).In univariate analysis, female, adenocarcinoma, Score Index for Radiosurgery in Brain Metastases (SIR) score $>5$, number of intracranial lesions $<3$, total volume of intracranial lesions $<7 \mathrm{cc}$, and history of EGFR-TKI treatment were significant predictors for better OS and IC-PFS(see Table 2). In multivariate analysis, SIR score $>5$, number of intracranial lesions $<3$, and history of EGFR-TKI treatment remained significant as favorable prognostic factors (see Table 2).

\section{Toxicities}

The radiation-induced acute toxicities were generally mild (grades 1-2). The most frequent toxicities were grade 2 alopecia (reported in 29 patients, 100\%), grade 1 radiation dermatitis (reported in 29 patients, 100\%), grades 1-2 headache (reported in 8 patients, 27.6\%), and grades 1-2 nausea (reported in 5 patients, 17.2\%). There were no grade 3 acute toxicities.

The radiation-induced late toxicities were reported in 25 patients, including grades 1 and 2 leukoencephalopathy in $17(58.6 \%)$ and $8(27.6 \%)$ patients, respectively; grades 1,2 , and 3 cognitive disturbance in 6 (20.7\%), 4 (13.8\%), and $4(13.8 \%)$ patients, respectively. All patients with grade 2 or 3 cognitive impairment also had grade 2

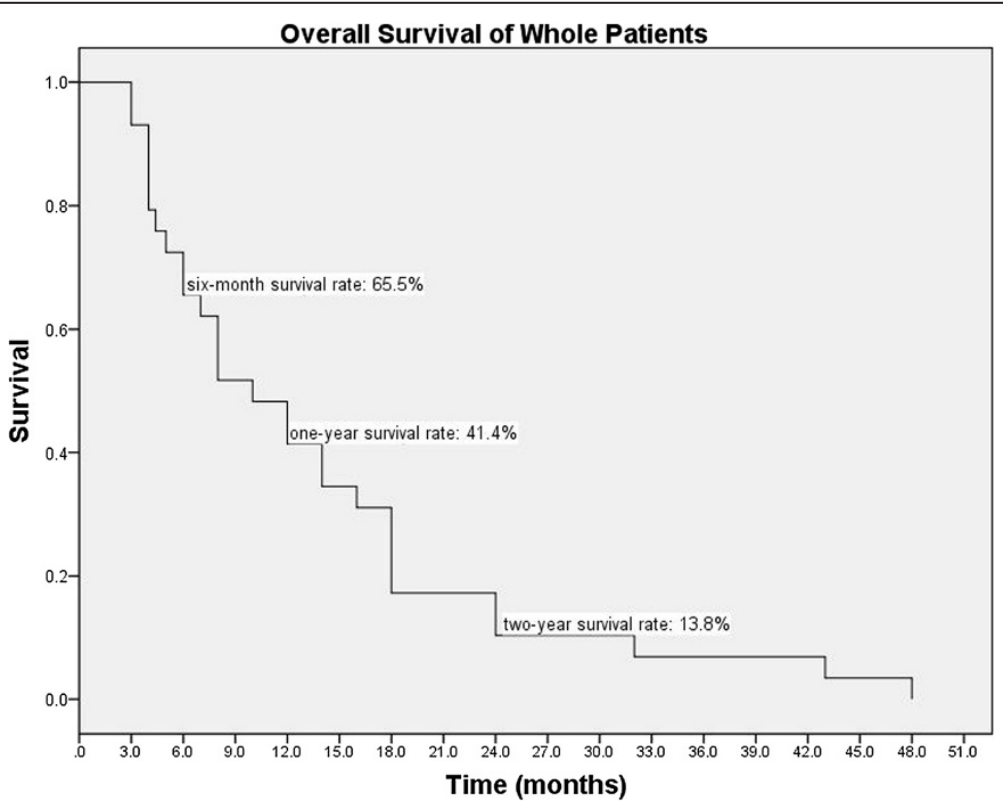

Figure 2 Overall survival of the whole patients. The Kaplan-Meier overall survival curve of whole group showed the six-month, one-year and two-year survival rates were $65.5 \%, 41.4 \%$ and $13.8 \%$, respectively. 


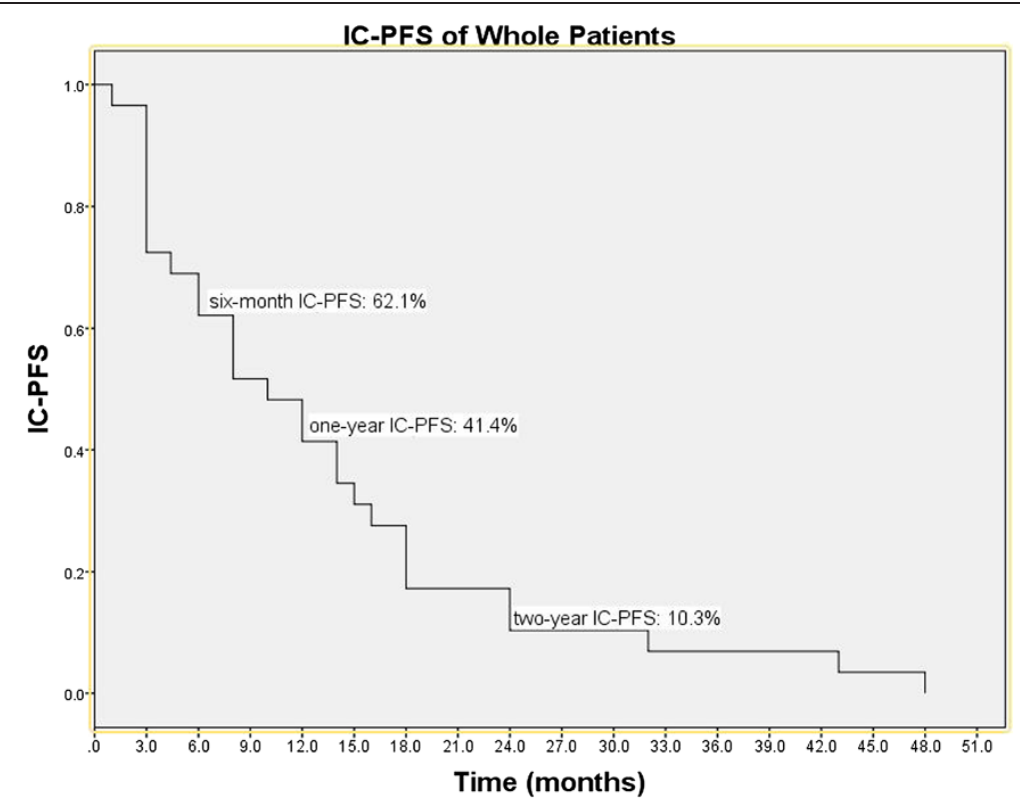

Figure 3 IC-PFS of the whole patients. The Kaplan-Meier IC-PFS curve of whole group showed the six-month, one-year and two-year IC-PFS rates were $62.1 \%, 41.4 \%$ and $10.3 \%$, respectively. Abbreviations: IC-PFS = intracranial progression-free survival.

leukoencephalopathy. Of 89 lesions, 3 (3.45\%) lesions from 2 (6.90\%) different patients demonstrated radiation necrosis after radiotherapy. In univariate analysis, female, age $\geq$ 60 year-old, and history of EGFR-TKI treatment were risk factors for grade 2 leukoencephalopathy, and only history of EGFR-TKI treatment remained statistically significant in multivariate analysis (see Table 2). The time from radiotherapy to the occurrence of grade 2 or 3 cognitive impairment was $2-24$ months with the median time of 9 months. The time from radiotherapy to the occurrence of grade 1 or 2 radiation leukoencephalopathy was 2-9 months with the median time of 6 months.

\section{Dosimetry}

The median GTV of individual lesions were $6.62 \mathrm{cc}$ (range: $2.41 \mathrm{cc}-70.74 \mathrm{cc}$ ), and the median whole brain volume were1420.9 cc (range: $1215.2 \mathrm{cc}-1587.5 \mathrm{cc}$ ). At the time of IG-IMRT boost, some region of normal brain tissue would have received more than 3-5 Gy/f. VXG was defined as volume of normal brain tissue receiving at least XGy per fraction during the SIB, and the V3G, V4G, and V5G in present study ranged from $47.90 \mathrm{cc}$ to $474.30 \mathrm{cc}$, $15.40 \mathrm{cc}$ to $241.26 \mathrm{cc}$, and $8.36 \mathrm{cc}$ to $128.30 \mathrm{cc}$, respectively. VX was defined as the percentage volume of normal brain receiving at least XGy per fraction during the SIB. The V3, V4, and V5 in present study ranged from $1.11 \%$ to $10.87 \%, 0.37 \%$ to $5.46 \%$, and $0.20 \%$ to $2.98 \%$, respectively. In the dosimetry analysis, there was no correlation between the incidence of grade 2 leukoencephalopathy and V3G-V5G or V3-V5 (see Table 3). However, number of intracranial lesions $>3$, maximum intracranial lesion volume $\geq 3 \mathrm{cc}$, and total volume of intracranial lesions $\geq 7$ cc were statistically significant associated with larger V3G-V5G and V3-V5 (see Table 3).

\section{Discussion}

WBRT plus sequential focal SRS/hfSRT boost is one of the most widely used therapeutic strategies for patients with limited brain metastases. However, evidence on efficacy and toxicities of WBRT plus simultaneous hfSRT are emerging recently. The phase I trial of WBRT plus SIB with helical tomotherapy showed that the delivery of $60 \mathrm{~Gy} / 10 \mathrm{f}$ synchronously with WBRT of 30 Gy was tolerable in patients with 1-3 brain metastases, and the Phase II trial is ongoing to examine its efficacy $[12,13]$. Just like helical tomotherapy, the Synergy IGRT system used in our study is one of integrated image-guided intensity-modulated-capable radiotherapy platforms. However, different from the more advanced arc-based IMRT such as helical tomotherapy, the radiation technology used in our study was a stepand-shoot IMRT which was more common and economically feasible in developing countries. Furthermore, only NSCLC patients were eligible in our study, and they were more homogeneous with respect to previous reports of WBRT plus SIB with helical tomotherapy, which enrolled patients without prescribing a limit to pathological type of primary cancer [12-14].

The reported one-year ICR and median survivals of patients with limited brain metastases received WBRT plus sequential focal hfSRT boost were $66 \%-86 \%$ and $7.5-13$ months [16-20]. Unlike reports above, approximately half of patients in our study had multiple $(\geq 3)$ or large ( $\geq 3 \mathrm{cc}$ ) 
Table 2 Univariate and multivariate analysis of IC-PFS, median survival and incidence of grade 2 leukoencephalopathy

\begin{tabular}{|c|c|c|c|c|c|c|c|c|c|}
\hline & $\begin{array}{l}\text { IC-PFS (m) } \\
\text { Median }\end{array}$ & $\begin{array}{l}\text { Univariate } \\
p \text {-value }\end{array}$ & $\begin{array}{l}\text { Multivariate } \\
p \text {-value }\end{array}$ & $\begin{array}{l}\text { MS } \\
(\mathrm{m})\end{array}$ & $\begin{array}{l}\text { Univariate } \\
p \text {-value }\end{array}$ & $\begin{array}{l}\text { Multivariate } \\
p \text {-value }\end{array}$ & $\begin{array}{l}\text { Leukoencephalopathy } \\
\text { No. of patients (\%) }\end{array}$ & $\begin{array}{l}\text { Univariate } \\
p \text {-value }\end{array}$ & $\begin{array}{l}\text { Multivariate } \\
p \text {-value }\end{array}$ \\
\hline \multicolumn{10}{|l|}{ Gender } \\
\hline Male & 6 & 0.020 & 0.869 & 7 & 0.019 & 0.983 & $3 / 20(15.5)$ & 0.024 & 0.562 \\
\hline Female & 18 & & & 18 & & & $5 / 9(55.6 \%)$ & & \\
\hline \multicolumn{10}{|l|}{ Age (years) } \\
\hline$\geq 60$ & 8 & 0.628 & & 8 & 0.719 & & 5/18 (27.8) & 0.794 & \\
\hline$<60$ & 12 & & & 12 & & & $3 / 11(27.3)$ & & \\
\hline \multicolumn{10}{|l|}{ KPS scores } \\
\hline$\geq 70$ & 12 & 0.251 & & 12 & 0.223 & & 5/19 (26.3) & 0.833 & \\
\hline$<70$ & 3 & & & 4.4 & & & $3 / 10(30)$ & & \\
\hline \multicolumn{10}{|l|}{ Pathology } \\
\hline Adenocarcinoma & 14 & 0.015 & 0.519 & 14 & 0.011 & 0.553 & $6 / 13(46.2)$ & 0.044 & 0.084 \\
\hline Non-adenocarcinoma & 3 & & & 4.4 & & & $2 / 16(12.5)$ & & \\
\hline \multicolumn{10}{|l|}{ RPA class } \\
\hline 2 & 12 & 0.266 & & 12 & 0.185 & & $5 / 19(26.3)$ & 0.833 & \\
\hline 3 & 3 & & & 4.4 & & & $3 / 10(30.0 \%)$ & & \\
\hline \multicolumn{10}{|l|}{ GPA scores } \\
\hline $0-1$ & 6 & 0.331 & & 7 & 0.188 & & 4/13 (30.8) & 0.730 & \\
\hline $1.5-3.5$ & 14 & & & 14 & & & $4 / 16(25 \%)$ & & \\
\hline \multicolumn{10}{|l|}{ SIR scores } \\
\hline$\leq 5$ & 3 & 0.001 & 0.044 & 4.4 & $<0.001$ & 0.021 & $5 / 13(38.5)$ & 0.238 & \\
\hline$>5$ & 14 & & & 14 & & & $3 / 16(18.75)$ & & \\
\hline \multicolumn{10}{|l|}{$\begin{array}{l}\text { History of EGFR-TKI } \\
\text { treatment }\end{array}$} \\
\hline Yes & 16 & 0.026 & 0.035 & 18 & 0.022 & 0.040 & 7/11 (63.6) & 0.001 & 0.010 \\
\hline No & 6 & & & 7 & & & $1 / 18(5.6)$ & & \\
\hline \multicolumn{10}{|l|}{ Number of lesions } \\
\hline$<3$ & 14 & 0.005 & 0.036 & 14 & 0.007 & 0.048 & $6 / 15(40.0)$ & 0.122 & \\
\hline$\geq 3$ & 3 & & & 6 & & & $2 / 14(14.3)$ & & \\
\hline \multicolumn{10}{|l|}{$\begin{array}{l}\text { Maximum lesion } \\
\text { volume }\end{array}$} \\
\hline$<3 c c$ & 14 & 0.209 & & 14 & 0.081 & & 4/12 (33.3) & 0.561 & \\
\hline$\geq 3 \mathrm{cc}$ & 4.4 & & & 6 & & & $4 / 17(23.5)$ & & \\
\hline \multicolumn{10}{|l|}{ Total volume of lesions } \\
\hline$<7 \mathrm{CC}$ & 14 & 0.032 & 0.232 & 14 & 0.037 & 0.256 & 5/15 (33.3) & 0.474 & \\
\hline$\geq 7 \mathrm{CC}$ & 3 & & & 6 & & & $3 / 14(21.4)$ & & \\
\hline Total & 10 & & & 10 & & & $8 / 29(27.6)$ & & \\
\hline
\end{tabular}

Abbreviations: IC-PFS = intracranial progression-free survival; MS = median survival; $\mathrm{m}=$ month; $\mathrm{RPA}=$ recursive partitioning analysis; $\mathrm{GPA}=\mathrm{graded}$ prognostic assessment; SIR = score index for radiosurgery in brain metastases; EGFR-TKI=epidermal growth factor receptor- tyrosine kinase inhibitor.

intracranial lesions, which were always excluded in other studies. However, the median survival and one-year ICR of whole patients in our study were 10 months and 62.9\%, which were close to previous data in above studies. Several grading systems are available for brain metastases, such as Graded Prognostic Assessment (GPA), Recursive Partitioning Analysis (RPA) and SIR. Higher level of RPA and lower scores of GPA and SIR are associated with worse survival of patients with brain metastases [21-24]. Similarly, the survival was better in RPA class II, GPA scores 1.5-3.5, and SIR $>5$ patients in our study. However, possibly because of the limited number of enrolled patients, only differences in survivals between patients with SIR $\leq 5$ and $>5$ were statistically significant. The number of lesions 
Table 3 Univariateanalysis of V3G-V5G and V3-V5

\begin{tabular}{|c|c|c|c|c|c|c|c|c|c|c|c|c|}
\hline & \multicolumn{2}{|l|}{ V3G (cc) } & \multicolumn{2}{|l|}{ V4G (cc) } & \multicolumn{2}{|l|}{ V5G (cc) } & \multicolumn{2}{|c|}{ V3 (\%) } & \multicolumn{2}{|c|}{ V4 (\%) } & \multicolumn{2}{|c|}{ V5 (\%) } \\
\hline & Mean \pm SD & $p$ & Mean \pm SD & $p$ & Mean \pm SD & $p$ & Mean \pm SD & $p$ & Mean \pm SD & $p$ & Mean \pm SD & $p$ \\
\hline \multicolumn{13}{|c|}{ leukoencephalopathy } \\
\hline Grade 0-1 & $204.94 \pm 150.85$ & 0.288 & $77.94 \pm 67.47$ & 0.316 & $34.12 \pm 30.99$ & 0.574 & $4.66 \pm 3.40$ & 0.102 & $1.77 \pm 1.52$ & 0.334 & $0.78 \pm 0.71$ & 0.609 \\
\hline Grade 2 & $128.60 \pm 80.62$ & & $51.08 \pm 49.53$ & & $27.14 \pm 24.85$ & & $3.00 \pm 1.81$ & & $1.18 \pm 1.12$ & & $0.63 \pm 0.57$ & \\
\hline \multicolumn{13}{|c|}{ Number of lesions } \\
\hline$<3$ & $126.05 \pm 115.60$ & 0.017 & $39.06 \pm 44.83$ & 0.004 & $18.65 \pm 17.00$ & 0.010 & $2.94 \pm 2.55$ & 0.020 & $0.91 \pm 0.98$ & 0.004 & $0.44 \pm 0.39$ & 0.013 \\
\hline$\geq 3$ & $245.84 \pm 136.82$ & & $104.24 \pm 64.15$ & & $46.70 \pm 32.90$ & & $5.57 \pm 3.14$ & & $2.36 \pm 1.47$ & & $1.05 \pm 0.76$ & \\
\hline \multicolumn{13}{|c|}{$\begin{array}{l}\text { Maximum lesion } \\
\text { volume }\end{array}$} \\
\hline$<3 \mathrm{cc}$ & $94.13 \pm 67.73$ & 0.004 & $35.77 \pm 27.52$ & 0.006 & $15.35 \pm 7.55$ & 0.003 & $2.20 \pm 1.42$ & 0.001 & $0.83 \pm 0.61$ & 0.006 & $0.36 \pm 0.17$ & 0.004 \\
\hline$\geq 3 \mathrm{cc}$ & $238.73 \pm 143.95$ & & $91.77 \pm 70.05$ & & $42.49 \pm 32.74$ & & $5.43 \pm 3.24$ & & $2.08 \pm 1.58$ & & $0.97 \pm 0.75$ & \\
\hline \multicolumn{13}{|l|}{$\begin{array}{l}\text { Total volume } \\
\text { of lesions }\end{array}$} \\
\hline$<7 \mathrm{CC}$ & $108.74 \pm 76.57$ & 0.002 & $35.82 \pm 31.48$ & 0.002 & $15.43 \pm 11.06$ & 0.001 & $2.55 \pm 1.75$ & 0.003 & $0.83 \pm 0.70$ & 0.002 & $0.36 \pm 0.25$ & 0.002 \\
\hline$\geq 7 \mathrm{cc}$ & $264.39 \pm 145.93$ & & $107.71 \pm 68.56$ & & $50.15 \pm 30.07$ & & $5.98 \pm 3.30$ & & $2.44 \pm 1.56$ & & $1.14 \pm 0.74$ & \\
\hline Total & $183.87 \pm 138.15$ & & $70.53 \pm 63.36$ & & $32.19 \pm 29.16$ & & $4.21 \pm 3.10$ & & $1.61 \pm 1.43$ & & $0.74 \pm 0.67$ & \\
\hline
\end{tabular}

Abbreviations: $\mathrm{VXG}=$. The volume of normal brain tissue receiving at least $\mathrm{XGy}$ per fraction during the $\mathrm{SIB} ; \mathrm{VX}=$. The percentage volume of normal brain receiving at least $X G y$ per fraction during the $S I B ; c c=$ cubic centimeter.

is another important factor affecting radiotherapy efficacy, and patients with limited number of brain metastases seem to have better outcomes. It has been reported that median survivals were 6.5-16 months following WBRT plus focal radiotherapy boost in patients with single intracranial lesion, corresponding to 5.8-13months in patients with multiple intracranial lesions $[8,9,16,17]$. Similarly, patients with number of lesions $<3$ showed better outcomes in our study, and the median survival was comparable to the data reported by other investigators $[11,17,20]$.

Several studies showed that the radiosensitivity of brain metastases is associated with the mutation status of epidermal growth factor receptor (EGFR) [25-27]. Compared to patients with the wild-type, those with activating EGFR mutations had higher response rates and better survival following WBRT (54\% VS. 24\%, $P=0.045 ; 17.3$ months $V S$. 6.6 months, $P=0.121$ ) [26]. EGFR-TKI, either alone or combined with WBRT, is effective in brain metastases of NSCLC especially for EGFR-mutated patients $[26,28,29]$. From the phase I and II trials of WBRT with concurrent and maintenance erlotinib in NSCLC with brain metastases, erlotinib in combination with WBRT was well tolerated and had a favorable efficacy. Moreover, EGFR-mutated patients had a better survival compared to those with wild-type (median survival: 19.1 months VS. 9.3 months) [29,30]. In present study, history of EGFR-TKI treatment was also a favorable prognostic factor for survival, and the median survival of 11 patients received concurrent and maintenance EGFR-TKI treatment was as long as 18 months. EGFR mutation status is not available in our study. However, most patients who received EGFR-TKI in this study were female $(72.7 \%)$ and had adenocarcinoma (81.8\%). Considering the evidence that Asian, female, nonsmoking, and adenocarcinoma patients were more likely to be EGFR mutated, and rates of EGFR mutation in brain metastases of NSCLC were 44\%-63\% in East Asian population $[31,32]$. We speculated that EGFR mutations might contribute to the better survival in the EGFR-TKI treated patients in present study.

Considering the concurrent WBRT, intracranial lesions received total boost doses of $30 \mathrm{~Gy} / 5 \mathrm{f}$ in our study. By using the $\alpha / \beta$ ratio of 12 Gy and LQC model (BED = nd $\left.\left[1+d /(\alpha / \beta)-d^{2} /(\alpha / \gamma)\right]\right)$, which was indicated to be suitable for calculating BED value of SRS or hfSRT for brain metastases [33], the BED value of total boost were $43.33 \mathrm{~Gy}$, which was comparable to other reports of brain metastases treated by hfSRT $[12,13,16-20,34]$. Late radiation toxicity of $13.8 \%$ grade 3 cognitive impairment in our group was comparable to previous data of $6 \%-11 \%$ grade 3 late toxicities from other studies $[16,17]$. The incidence of radiation necrosis was one of the major concerns in late toxicities from WBRT plus focal radiotherapy boost, but it was quite infrequent in our study, and was similar to other reports of WBRT plus focal hfSRT boost [10,16-18]. Leukoencephalopathy and cognitive impairment were primary late toxicities in present study, and only history of EGFR-TKI treatment was a risk factor for grade 2 leukoencephalopathy in multivariate analysis, which had not been reported by other studies. Patients who received EGFR-TKI treatment had the longer survival, which might partly explain the higher incidence of late toxicities in these patients. It has been reported that the EGFR-TKI plus concomitant WBRT may have synergy 
effect in brain metastases from NSCLC, the ORR, ICR, and IC-PFS were significantly higher in gefitinib plus WBRT compared with gefitinib alone (ORR: 64.4\% VS. 26.7\%, $P<0.001$; DCR: 71.1\% VS. 42.2\%, $P=0.006$; ICPFS: 10.6 months VS. 6.57 months, $P<0.001$ ) [35]. It is a reasonable assumption that the EGFR-TKI plus concomitant brain radiotherapy might also have synergy neurotoxicity, and it might be another reason for the higher incidence of late toxicities in patients with EGFRTKI treatment. However, considering the limited number of patients in our study, it may need more preclinical and clinical data to support this assumption.

This retrospective study had many limitations such as heterogeneity and limited number of enrolled patients, lack of phase I data, lack of health-related quality of life (HRQoL) data, and lack of neurocognative testing data. We look forward to that the ongoing phase II trial of SIB with helical tomotherapy for $1-3$ brain metastases will give us more information [13].

\section{Conclusions}

WBRT plus SIB with IG-IMRT is a tolerable and effective treatment for NSCLC patients with inoperable brain metastases, especially for those with SIR score $>5$, number of intracranial lesions $<3$, and history of EGFR-TKI treatment. However, the results of present study need to be examined by the prospective investigations.

\begin{abstract}
Abbreviations
BED: Biological effective dose; CBCT: Cone beam computed tomography; CR: Complete response; CTCAE: National cancer institute common terminology criteria for adverse events; CTV: Clinical target volume; CTVL: Clinical target volume of lesion; EGFR: Epidermal growth factor receptor; EGFR-TKI: Epidermal growth factor receptor tyrosine kinase inhibitor; GPA: Graded prognostic assessment; GTV-L: Gross tumor volume of lesion; hfSRT: Hypofractionated stereotactic radiotherapy; HRQoL: Health-related quality of life; ICR: Intracranial control rate; IC-PFS: Intracranial progressionfree survival; IMRT: intensity-modulated radiotherapy; IG-IMRT: Image guided intensity-modulated radiotherapy; KPS: Karnofsky performance status; LBFR: Local brain failure rate; LQ: Linear-quadratic; MS: Median survival; NSCLC: Non-small cell lung cancer; ORR: Objective response rate; OS: Overall survival; PR: Partial response; RPA: Recursive partitioning analysis; PTV: Planning target volume; PTV-L: Planning target volume of lesion; RBFR: Regional brain failure rate; SD: Stable disease; SIB: Simultaneous in-fieldboost; SIR: Score index for radiosurgery in brain metastases; SRS: Stereotactic radiosurgery; V3G: The volume of normal brain tissue received more than 3 Gy per fraction; V4G: The volume of normal brain tissue received more than 4 Gy per fraction; V5G: The volume of normal brain tissue received more than 5 Gy per fraction; V3: The percentage of normal brain volume exceeding 3 Gy per fraction; $V 4$ : The percentage of normal brain volume exceeding 4 Gy per fraction; V5: The percentage of normal brain volume exceeding 5 Gy per fraction; WBRT: Whole brain radiotherapy; WHO: World Health Organization; XVI: X-ray volumetric images.
\end{abstract}

\section{Competing interests}

There is no actual or potential conflict of interest in this study.

\section{Authors' contributions}

LZ participated in its design and drafted the manuscript. $J L$ helped to review medical records and draft the manuscript. JX helped to analyze the data of local tumor control and survival. YX helped to review medical records. YG and LD helped to draft the manuscript and participated in coordination. SW helped to analyze the data of dosimetry. RZ helped to analyze the data of dosimetry. ZD helped to review medical records. YL designed the study and participated in coordination. All authors read and approved the final manuscript.

\section{Acknowledgements}

This work was supported by National Natural Science Fund of China (81301935, 81172131).

\section{Author details}

${ }^{1}$ Department of Thoracic Cancer, Cancer Center, West China Hospital of Sichuan University, Chengdu, Sichuan Province, China. ${ }^{2}$ Department of Oncology, Chengdu First People's Hospital, Chengdu, Sichuan Province, China. ${ }^{3}$ Center of Radiation Physics, Cancer Center, West China Hospital of Sichuan University, Chengdu, Sichuan Province, China. ${ }^{4}$ State Key Laboratory of Biotherapy, West China Hospital of Sichuan University, Chengdu, Chengdu, Sichuan Province, China.

Received: 3 February 2014 Accepted: 28 April 2014

Published: 21 May 2014

\section{References}

1. Mujoomdar A, Austin JH, Malhotra R, Powell CA, Pearson GD, Shiau MC, Raftopoulos $\mathrm{H}$ : Clinical predictors of metastatic disease to the brain from non-small cell lung carcinoma: primary tumor size, cell type, and lymph node metastases. Radiology 2007, 242:882-888.

2. Khuntia D, Brown P, Li J: Mehta MP:Whole-brain radiotherapy in the management of brain metastasis. J Clin Oncol 2006, 24:1295-1304.

3. Flickinger JC, Kondziolka D, Pollock BE, Maitz AH: Lunsford LD: Complications from arteriovenous malformation radiosurgery: multivariate analysis and risk modeling. Int J Radiat Oncol Biol Phys 1997, 38:485-490.

4. Schlienger M, Nataf F, Huguet F, Pene F, Foulquier JN, Orthuon A, Roux FX, Touboul E: Hypofractionated stereotactic radiotherapy for brain metastases. Cancer Radiother 2010, 14:119-127.

5. Cardinale RM, Benedict SH, Wu Q, Zwicker RD, Gaballa HE, Mohan R: A comparison of three stereotactic radiotherapy techniques; ARCS vs. noncoplanar fixed fields vs. intensity modulation. Int I Radiat Oncol Biol Phys 1998, 42:431-436.

6. Ingrosso G, Miceli R, Fedele D, Ponti E, Benassi M, Barbarino R, Di Murro L, Giudice E, Santarelli F, Santoni R: Cone-beam computed tomography in hypofractionated stereotactic radiotherapy for brain metastases. Radiat Oncol 2012, 7:54

7. Dincoglan F, Beyzadeoglu M, Sager O, Oysul K, Sirin S, Surenkok S, Gamsiz H, Uysal B, Demiral S, Dirican B: Image-guided positioning in intracranial noninvasive stereotactic radiosurgery for the treatment of brain metastasis. Tumori 2012, 98:630-635.

8. Andrews DW, Scott CB, Sperduto PW, Flanders AE, Gaspar LE, Schell MC, Werner-Wasik M, Demas W, Ryu J, Bahary JP, Souhami L, Rotman M, Mehta MP, Curran WJ Jr: Whole brain radiation therapy with or without stereotactic radiosurgery boost for patients with one to three brain metastases: phase III results of the RTOG 9508 randomised trial. Lancet 2004, 363:1665-1672.

9. Aoyama H, Shirato H, Tago M, Nakagawa K, Toyoda T, Hatano K, Kenjyo M, Oya N, Hirota S, Shioura H, Kunieda E, Inomata T, Hayakawa K, Katoh N, Kobashi G: Stereotactic radiosurgery plus whole-brain radiation therapy vs stereotactic radiosurgery alone for treatment of brain metastases: a randomized controlled trial. JAMA 2006, 295:2483-2491.

10. Jiang XS, Xiao JP, Zhang Y, Xu YJ, Li XP, Chen XJ, Huang XD, Yi JL, Gao L, Li YX: Hypofractionated stereotactic radiotherapy for brain metastases larger than three centimeters. Radiat Oncol 2012, 7:36.

11. Serizawa T, Yamamoto M, Sato Y, Higuchi Y, Nagano O, Kawabe T, Matsuda S, Ono J, Saeki N, Hatano M, Hirai T: Gamma Knife surgery as sole treatment for multiple brain metastases: 2-center retrospective review of 1508 cases meeting the inclusion criteria of the JLGK0901 multiinstitutional prospective study. J Neurosurg 2010, 113(Suppl):48-52.

12. Rodrigues G, Yartsev S, Yaremko B, Perera F, Dar AR, Hammond A, Lock M, Yu E, Ash R, Caudrelier JM, Khuntia D, Bailey L, Bauman G: Phase I trial of simultaneous in-field boost with helical tomotherapy for patients with one to three brain metastases. Int J Radiat Oncol Biol Phys 2011, 80:1128-1133.

13. Rodrigues G, Yartsev S, Tay K, Pond GR, Lagerwaard F, Bauman G: A phase II multi-institutional study assessing simultaneous in-field boost helical tomotherapy for 1-3 brain metastases. Radiation Oncology 2012, 7:42. 
14. Rodrigues $G$, Eppinga W, Lagerwaard F, de Haan P, Haasbeek C, Perera F, Slotman B, Yaremko B, Yartsev S, Bauman G: A pooled analysis of arc-based image-guided simultaneous integrated boost radiation therapy for oligometastatic brain metastases. Radiotherapy and Oncology 2012, 102:180-186.

15. Gupta T, Basu A, Master Z, Jalali R, Munshi A, Sarin R: Planning and delivery of whole brain radiation therapy with simultaneous integrated boost to brain metastases and synchronous limited-field thoracic radiotherapy using helical tomotherapy: a preliminary experience. Technol Cancer Res Treat 2009, 8:15-22.

16. De Potter B, De Meerleer G, De Neve W, Boterberg T, Speleers B, Ost P: Hypofractionated frameless stereotactic intensity-modulated radiotherapy with whole brain radiotherapy for the treatment of 1-3 brain metastases. Neurol Sci 2013, 34:647-653.

17. Ma LH, Li G, Zhang HW, Wang ZY, Dang J, Zhang S, Yao L, Zhang XM: Hypofractionated stereotactic radiotherapy with or without whole-brain radiotherapy for patients with newly diagnosed brain metastases from non-small cell lung cancer. J Neurosurg 2012, 117(Suppl):49-56.

18. Kwon AK, Dibiase SJ, Wang B, Hughes SL, Milcarek B, Zhu Y: Hypofractionated stereotactic radiotherapy for the treatment of brain metastases. Cancer 2009, 115:890-898.

19. Marchetti M, Milanesi I, Falcone C, De Santis M, Fumagalli L, Brait L, Bianchi L, Fariselli L: Hypofractionated stereotactic radiotherapy for oligometastases in the brain: a single-institution experience. Neurol Sci 2011, 32:393-399.

20. Giubilei C, Ingrosso G, D'Andrea M, Benassi M, Santoni R: Hypofractionated stereotactic radiotherapy in combination with whole brain radiotherapy for brain metastases. J Neurooncol 2009, 91:207-212.

21. Serizawa T, Higuchi Y, Nagano O, Hirai T, Ono J, Saeki N, Miyakawa A: Testing different brain metastasis grading systems in stereotactic radiosurgery: Radiation Therapy Oncology Group's RPA, SIR, BSBM, GPA and modified RPA. J Neurosurg 2012, 117(Suppl):31-37.

22. Sperduto PW, Kased N, Roberge D, Xu Z, Shanley R, Luo X, Sneed PK, Chao ST, Weil RJ, Suh J, Bhatt A, Jensen AW, Brown PD, Shih HA, Kirkpatrick J, Gaspar LE, Fiveash JB, Chiang V, Knisely JP, Sperduto CM, Lin N, Mehta M: Summary report on the graded prognostic assessment: an accurate and facile diagnosis-specific tool to estimate survival for patients with brain metastases. J Clin Oncol 2012, 30:419-425.

23. Gaspar L, Scott C, Rotman M, Asbell S, Phillips T, Wasserman T, McKenna WG, Byhardt R: Recursive partitioning analysis (RPA) of prognostic factors in three Radiation Therapy Oncology Group (RTOG) brain metastases trials. Int J Radiat Oncol Biol Phys 1997, 37:745-751.

24. Weltman E, Salvajoli JV, Brandt RA, de Morais Hanriot R, Prisco FE, Cruz JC, de Oliveira Borges SR, Wajsbrot DB: Radiosurgery for brain metastases: a score index for predicting prognosis. Int J Radiat Oncol Biol Phys 2000, 46:1155-1161

25. Eichler AF, Kahle KT, Wang DL, Joshi VA, Willers H, Engelman JA, Lynch TJ, Sequist LV: EGFR mutation status and survival after diagnosis of brain metastasis in nonsmall cell lung cancer. Neuro Oncol 2010, 12:1 193-1199.

26. Gow CH, Chien CR, Chang YL, Chiu YH, Kuo SH, Shih JY, Chang YC, Yu CJ, Yang $\mathrm{CH}$, Yang PC: Radiotherapy in lung adenocarcinoma with brain metastases: effects of activating epidermal growth factor receptor mutations on clinical response. Clinical Cancer Research 2008, 14:162-168.

27. Johung KL, Yao X, Li F, Yu JB, Gettinger SN, Goldberg S, Decker RH, Hess JA, Chiang VL, Contessa JN: A clinical model for identifying radiosensitive tumor genotypes in non-small cell lung cancer. Clin Cancer Res 2013, 19:5523-5532

28. Porta R, Sanchez-Torres JM, Paz-Ares L, Massuti B, Reguart N, Mayo C, Lianes P, Queralt C, Guillem V, Salinas P, Catot S, Isla D, Pradas A, Gurpide A, de Castro J, Polo E, Puig T, Taron M, Colomer R, Rosell R: Brain metastases from lung cancer responding to erlotinib: the importance of EGFR mutation. Eur Respir J 2011, 37:624-631.

29. Welsh JW, Komaki R, Amini A, Munsell MF, Unger W, Allen PK, Chang JY, Wefel JS, McGovern SL, Garland LL, Chen SS, Holt J, Liao Z, Brown P, Sulman E, Heymach $\mathrm{JV}$, Kim ES, Stea B: Phase II trial of erlotinib plus concurrent whole-brain radiation therapy for patients with brain metastases from non-smallcell lung cancer. J Clin Oncol 2013, 31:895-902.

30. Lind JS, Lagerwaard FJ, Smit EF, Senan S: Phase I study of concurrent whole brain radiotherapy and erlotinib for multiple brain metastases from non-small-cell lung cancer. Int J Radiat Oncol Biol Phys 2009, 74:1391-1396
31. Rosell R, Moran T, Queralt C, Porta R, Cardenal F, Camps C, Majem M, LopezVivanco G, Isla D, Provencio M, Insa A, Massuti B, Gonzalez-Larriba JL, Paz-Ares L, Bover I, Garcia-Campelo R, Moreno MA, Catot S, Rolfo C, Reguart N, Palmero R, Sanchez JM, Bastus R, Mayo C, Bertran-Alamillo J, Molina MA, Sanchez JJ, Taron M: Screening for epidermal growth factor receptor mutations in lung cancer. N Engl J Med 2009, 361:958-967.

32. Burel-Vandenbos F, Ambrosetti D, Coutts M: Pedeutour F:EGFR mutation status in brain metastases of non-small cell lung carcinoma. J Neurooncol 2013, 111:1-10.

33. Wiggenraad R, Kanter AV-d, Kal HB, Taphoorn M, Vissers T, Struikmans H: Dose-effect relation in stereotactic radiotherapy for brain metastases. A systematic review. Radiotherapy and Oncology 2011, 98:292-297.

34. Narayana A, Chang J, Yenice K, Chan K, Lymberis S, Brennan C, Gutin PH: Hypofractionated stereotactic radiotherapy using intensity-modulated radiotherapy in patients with one or two brain metastases. Stereotact Funct Neurosurg 2007, 85:82-87.

35. Zeng YD, Zhang L, Liao H, Liang Y, Xu F, Liu JL, Dinglin XX, Chen LK: Gefitinib alone or with concomitant whole brain radiotherapy for patients with brain metastasis from non-small-cell lung cancer: a retrospective study. Asian Pac J Cancer Prev 2012, 13:909-914.

\section{doi:10.1186/1748-717X-9-117}

Cite this article as: Zhou et al:: Whole brain radiotherapy plus simultaneous in-field boost with image guided intensity-modulated radiotherapy for brain metastases of non-small cell lung cancer. Radiation Oncology 2014 9:117.

\section{Submit your next manuscript to BioMed Central and take full advantage of:}

- Convenient online submission

- Thorough peer review

- No space constraints or color figure charges

- Immediate publication on acceptance

- Inclusion in PubMed, CAS, Scopus and Google Scholar

- Research which is freely available for redistribution 